Journal of

\title{
Management of Maxillary Flabby Tissue \& Highly Resorbed Mandibular Ridges
}

\author{
Krishna Lahoti* \\ Professor \& Post Graduate Guide, Department of Prosthodontics, Swargiya Dadasaheb kalmegh Smruti Dental Col- \\ lege \& Hospital, Nagpur 441110 Maharashtra
}

${ }^{*}$ Corresponding author: Krishna Lahoti, Professor \& Post Graduate Guide, Department of Prosthodontics, Swargiya Dadasaheb kalmegh Smruti Dental College \& Hospital, Nagpur 441110 Maharashtra, E-mail: dentistksl@rediffmail.com

Received Date: June 20, 2016; Accepted Date: September 01, 2016; Published Date: September 02, 2016

Citation: Krishna Lahoti (2016) Management of Maxillary Flabby Tissue \& Highly Resorbed Mandibular Ridges. J Dent Oral Health 1: 1-5.

\begin{abstract}
Prosthodontic rehabilitation of a patient with poorly resorbed ridges in a conventional manner is a difficult task. Modifications in the treatment procedures should be considered to fulfill the patient's functional and esthetic desires. The key to successful denture therapy lies in precise execution of the treatment plan formulated by evaluation of a detailed comprehensive history and thorough examination. Such a treatment is based on M Muller Devan's principles of preservation of what already exists than the mere replacement of what is missing [1]. This article provides detailed treatment planning for poorly resorbed edentulous ridges.
\end{abstract}

\section{Introduction}

Complete dentures are functioning in the oral cavity of geriatric patients; they must be fabricated in such a way that they are in harmony with the normal neuromuscular function. All oral functions, such as Phonetics, mastication, Esthetics, swallowing, smiling, and laughing, involve the synergistic actions of muscles of the tongue, lips, cheeks, and floor of the mouth which are very complex and highly individual. Failure to give the cardinal importance to position of tooth and polished surface often results in dentures which are unstable and unsatisfactory, even though they were skillfully planned, designed and expertly constructed. The coordination of complete dentures with the neuromuscular function is the foundation of successful, stable dentures [2]. After loss of all teeth, there exists within the oral cavity a void which is the potential denture space. The neutral zone is the potential space between the lips and cheeks on one side and the tongue on the other, that area or position where the forces between the tongue and cheeks or lips are equal [3]. Improper arrangement of teeth \& polished surface may lead to failure of the prosthesis. This is particularly true for patients with reduced mandibular residual ridges, yielding flat or concave foundations due to severe bone loss. The unstable lower complete denture is a continuing problem for Dental Practitioners [4].

\section{Case Report}

A 78-year-old male patient had referred to the Department of Prosthodontics at Swargiya Dadasaheb Kalmegh Smruti Dental College \& Hospital, Nagpur with the complaints of not being able to chew properly, loosening of upper and lower denture and poor esthetics for the past 3 years. He also had complaint of movement of mandibular denture while swallowing and speaking. In extra- oral examination of patient, hollow cheeks with loss of support for lips \& cheeks can be readily made out (Figure 1). Intra-oral clinical Examination of the patient revealed poorly resorbed Maxillary \& Mandibular Ridges. Flabby \& mobile tissue was tissue was present in maxillary anterior area (Figure 2). Poorly resorbed knife edge Mandibular ridge was clearly evident (Figure 3). Orthopantomogram (OPG) confirmed the extensive bone loss in both the arches with knife edge ridge in mandibular arch (Figure 4). Vical \& swoop Analyses was made to quantify the bone loss in mandibular arch (Figure 5). Examination of existing denture, made 10 years back, showed overextended flanges \& severe attrition of occlusal surface of artificial teeth. Denture had lost vertical \& centric Relations. Extrinsic Stains can be seen on polished surface \& even tissue surface appears to be smooth (Figure 6). 


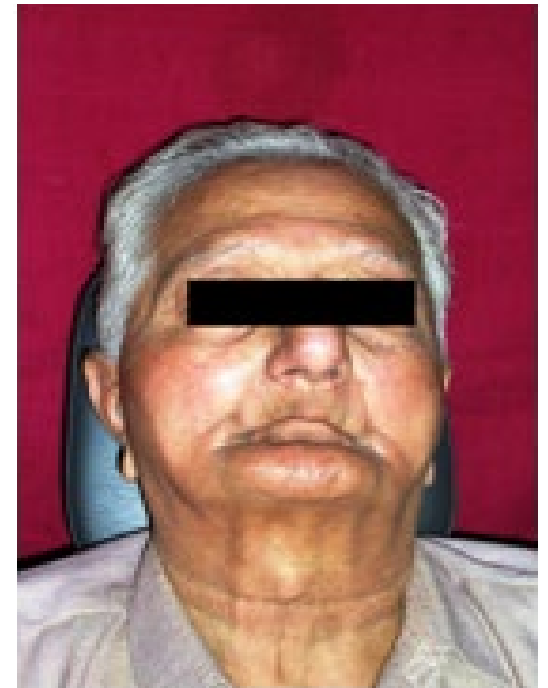

Figure 1: Pre-operative Extra oral View.

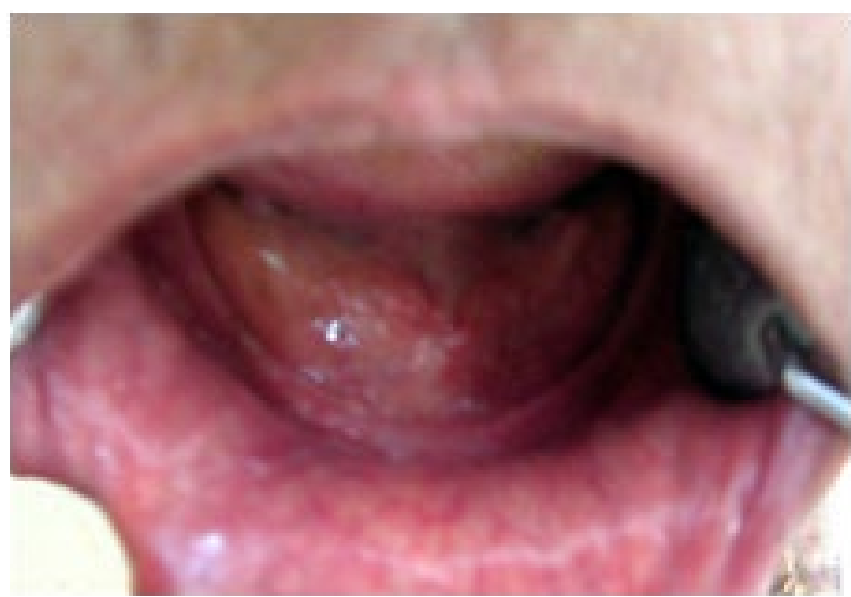

Figure 3: Mandibular Edentulous Knife edge Ridge.

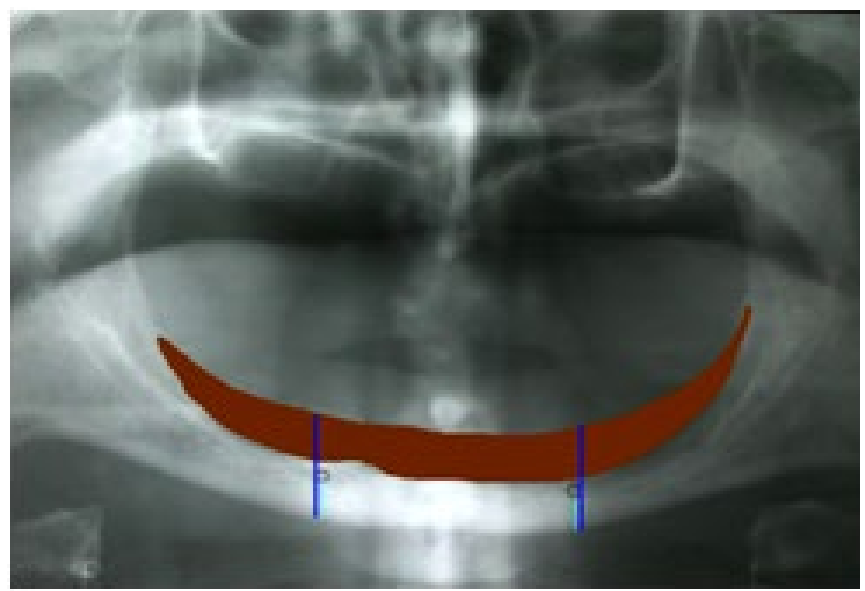

Figure 5: Vical \& swoop Analysis on OPG.

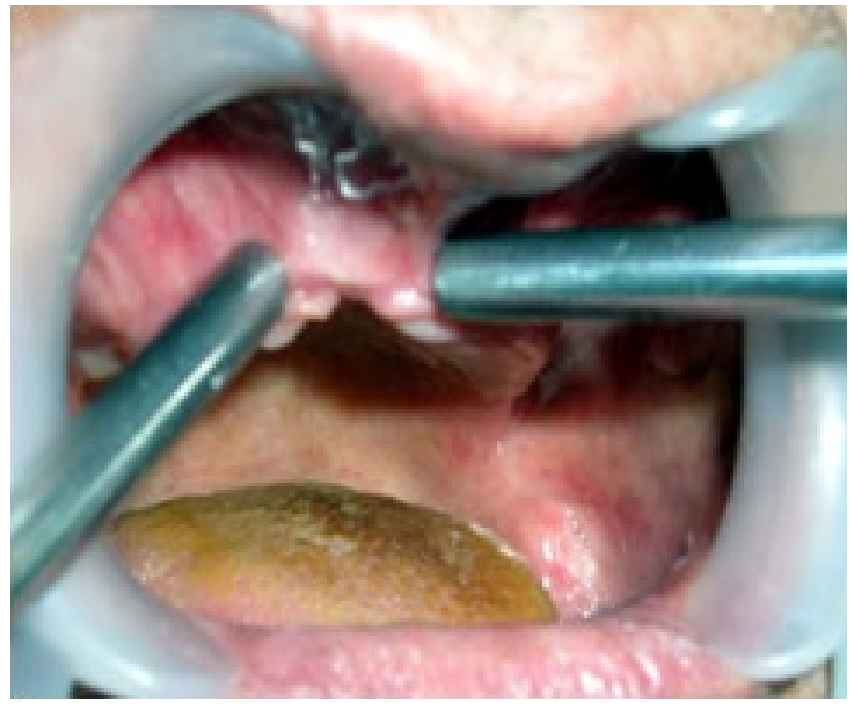

Figure 2: Maxillary Edentulous Ridge with Flabby Tissue.

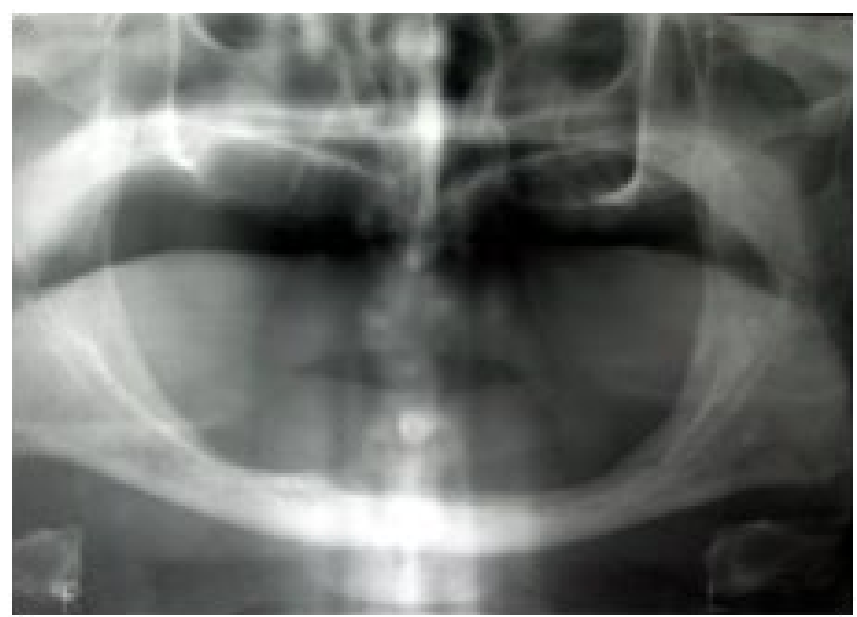

Figure 4: OPG.

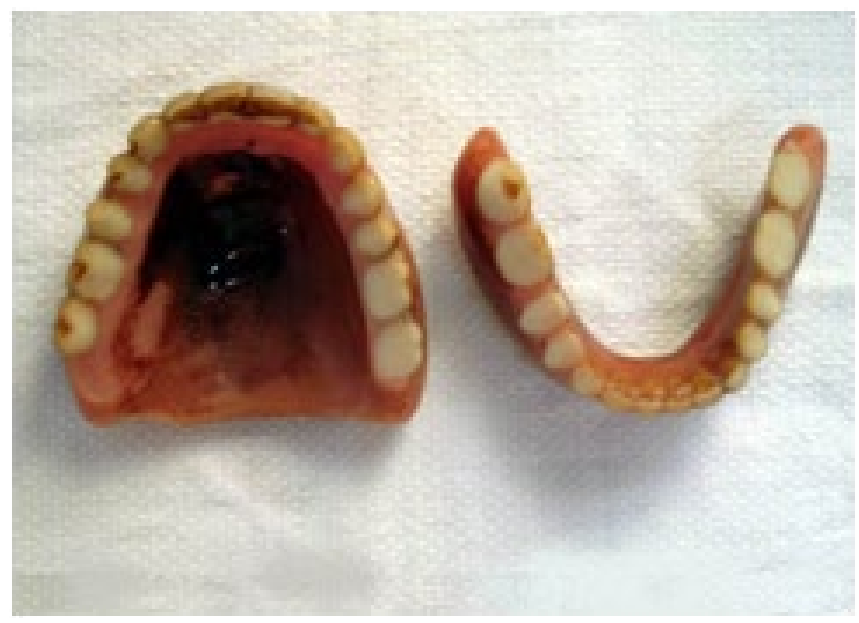

Figure 6: Previous Denture. 
Patient was On Insulin for uncontrolled Diabetes mellitus for last 13 years. Four months back, Patient had undergone Coronary Artery Bypass Graft (CABG) Surgery for cardiac ailment. He was on anti- hypertensive \& anti- coagulant therapy. So, the patient was informed of all the options available for the treatment including implants, but due to his dearranged medical profile, implant was discarded from treatment options and treatment chosen was esthetically and functionally viable for him. This article describes a simple clinical approach for fabrication of denture, which had good retention, stability, and esthetics for the patient. While designing Treatment plan, special emphasis was given to improve Support, retention, stability, esthetics, Comfort \& Preservation of remaining tissues. Maximal extension of the denture base with maximal area of contact between mucosa membrane and denture base so as to have intimate contact of the denture base and its basal seat was important to get our goal. First, the primary impression of maxillary \& mandibular edentulous ridges was made by irreversible hydrocolloid on the stock metal tray to record the mucosa in static form (Figure 7). Cast was poured in Type II Gypsum Product (Dental plaster). Over the cast, Mark the flabby ridge area on the cast \& special tray with proper spacer was fabricated using Tray material resin. The tray was trimmed $2 \mathrm{~mm}$ short of margin \& verified for extension in the mouth. Border molding was done using Low fusing impression compound in segments with proper tempering to avoid tissue injury.

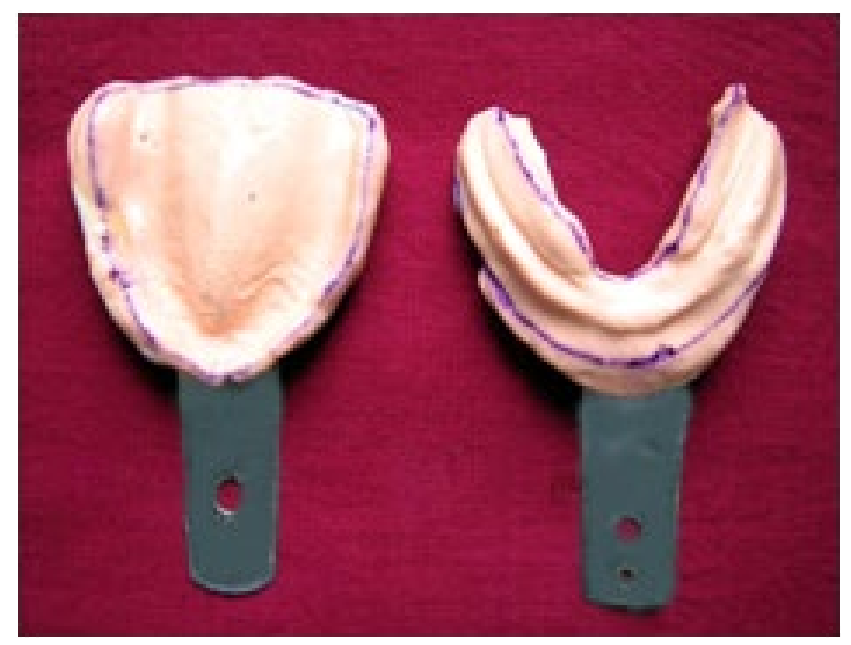

Figure 7: Primary Impression made by Irreversible Hydrocolloid.

After removing spacer, the maxillary wash impression using Zinc Oxide Eugenol impression paste was made. A window was made on the marked area for flabby tissue \& again verified intra-orally. Paint Impression Plaster on the area of flabby tissue using hair brush to record the tissue in most passive form so that distortion of the tissue can be avoided. After setting of impression plaster, the entire tray was removed from maxillary arch. For mandibular ridge, after removing spacer, tray adhesive was applied on tissue surface \& allowed to dry for 10 minutes. Then, light viscosity addition silicone was loaded on the tray \& immediately wash impression was made \& material is allowed to set for 4 minutes (Figure 8).

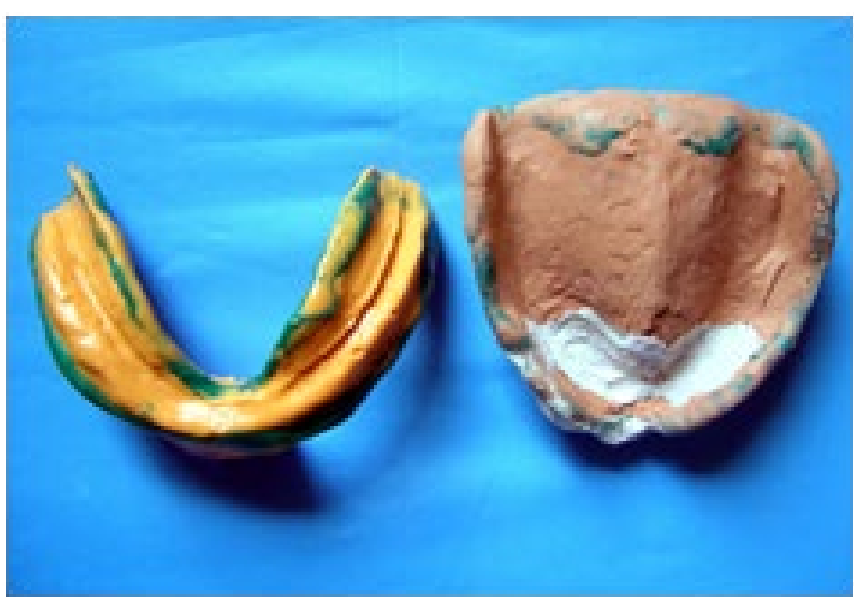

Figure 8: Final Impression.

After disinfection, Final Cast was poured in Type III Gypsum Product (Dental Stone).

The temporary record bases were prepared on the final cast using Auto-polymerizing Acrylic resin. By using spring bow, the maxillary cast was oriented to the Hanau wide view articulator. The vertical \& centric Jaw relation was done using Niswonger's Technique \& Inter-occlusal wax check bite record method respectively. To improve the Stability, extra care was given on the occlusal plane level, Teeth arrangement in Neutral Zone \& use of Non Anatomic teeth. The mandibular occlusal plane was kept $2 / 3$ rd to the retromolar pad so that horizontal movement of the mandibular denture can be prevented.

For Neutral Zone recording, maxillary \& mandibular rim is made in medium fusing impression compound \& adjusted as in normal registration for a complete denture. Only core portion of Impression compound is left to record Neutral Zone. Tissue conditioner is applied on facial as well as palatal \& lingual surfaces of compound rim \& patient is asked to talk and swallow, and drink some water. After 10 minutes of dynamic manipulations of lips, cheeks \& tongue, the entire assembly was removed from oral cavity \& cleaned (Figure 9). The Tissue conditioner would have been molded by the patient's musculature into a position of balance. The plaster indices were made on the assembly (Figure 10).

The Non Anatomic Teeth arrangement \& waxing of polished surface of the denture was done by using plaster indices to have maximum stability (Figure 11). Try-in of the denture was done in patient (Figure 12). After patient's consent, the denture was processed using Heat cured polymethyl methacrylate denture base resin. Laboratory remount was done $\&$ minute processing error was rectifies. The polished denture was ready for denture insertion (Figure 13). There was tremendous improvement of Extra-oral \& Intra- oral appearance of the patient. Patient was appeared to have regained confidence on his face (Figure 14). The instruction regarding maintenance \& recall were given. Patient recalled immediately 24 hours after denture delivery \& minor occlusal correction was done. Recall was monitored for 1week, 1 month, 3 months, 6 months \& for 1 year. Patient was completely satisfied in terms of retention, mastication, speech, comfort \& esthetics. 


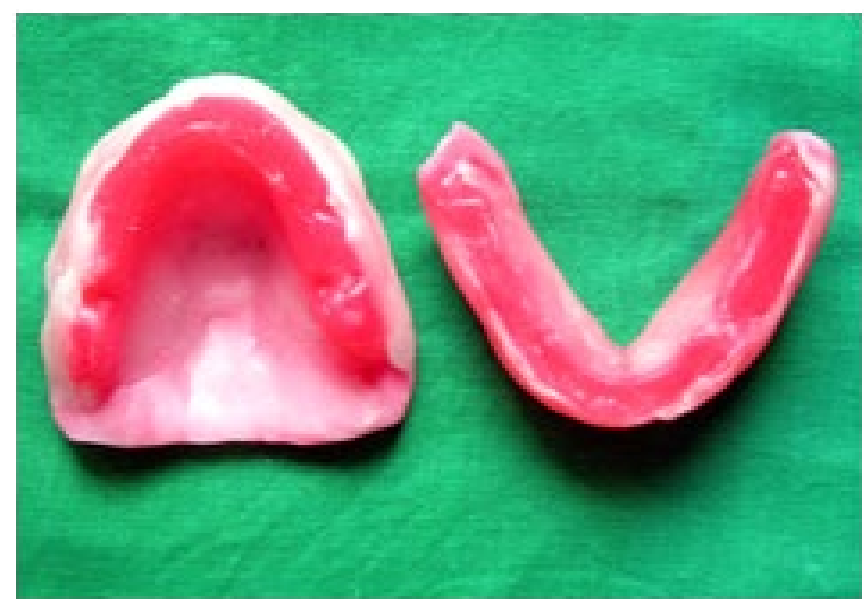

Figure 9: Rim with Neutral Zone Recording

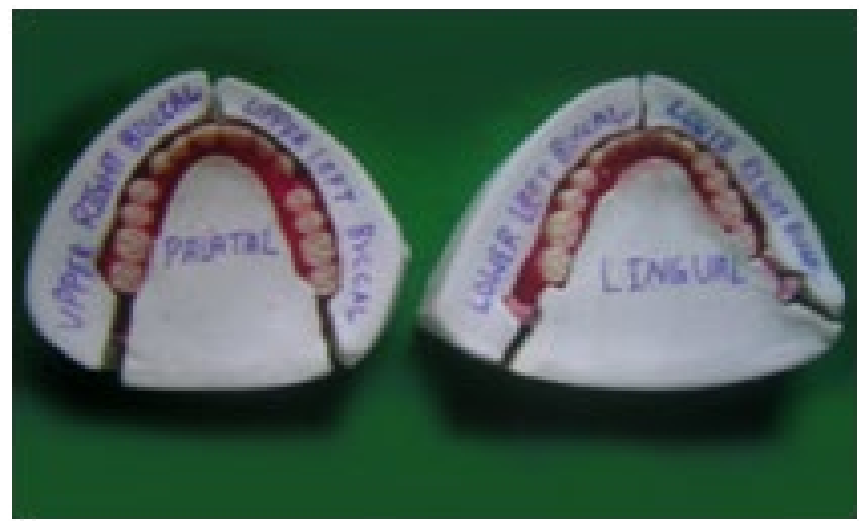

Figure 11: Teeth arrangement in Neutral Zone.

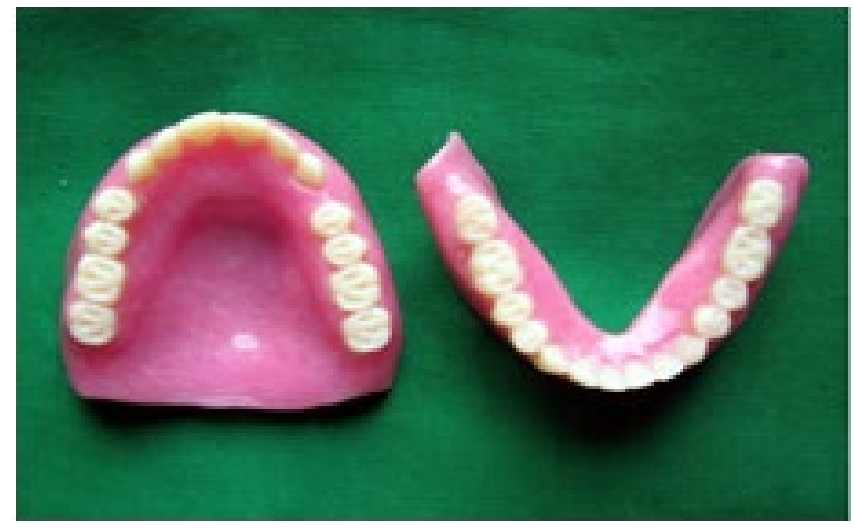

Figure 13: Finished complete denture.

\section{Discussion}

The residual alveolar ridge consists of denture-bearing mucosa, submucosa, periosteum, and underlying alveolar bone [5]. Residual bone is that part of alveolar ridge which remains after the teeth have been lost. After the loss of tooth, the alveoli that contained root are filled with new bone. This alveolar process becomes the residual ridge which is the foundation for the denture. The mean denture-bearing area of maxilla \& mandible is $22.96 \& 12.25 \mathrm{~cm} 2$ respectively. We have used the clinical techniques to improve support, retention, and stability of the lower denture. We ensured the maximal contact between mucosa membrane and denture base and intimate contact of denture base and basal seat area.

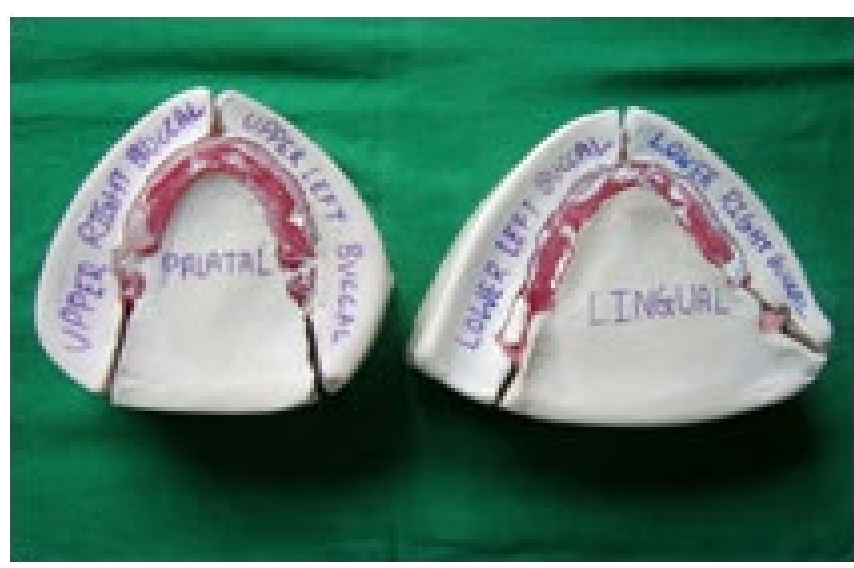

Figure 10: Neutral Zone Rim with plaster indices.

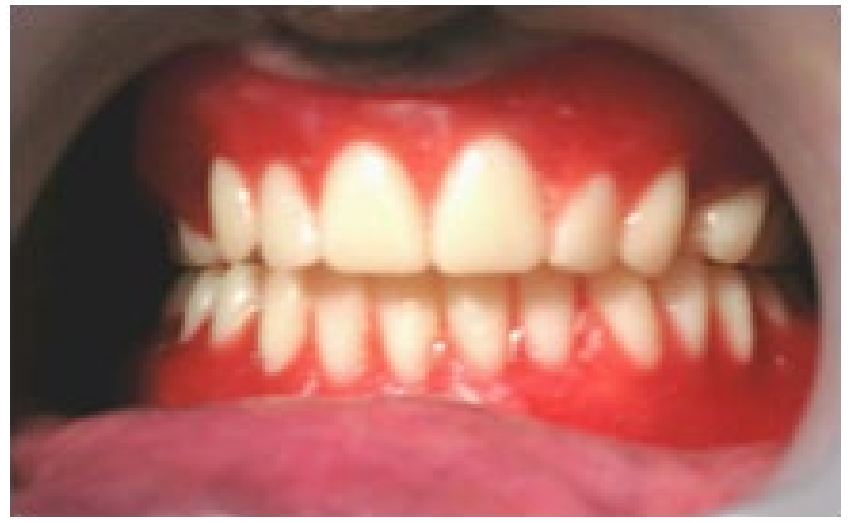

Figure 12: Intraoral view of waxed up denture during Try-in.

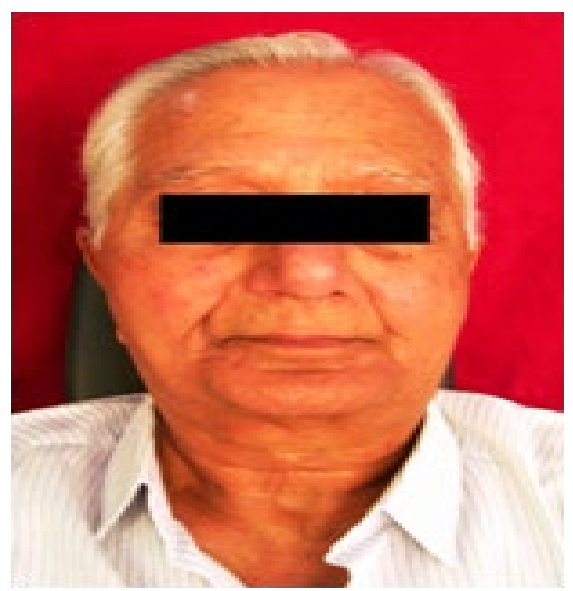

Figure 14: Post-operative Extra oral View.

In this case, we had flabby tissue in maxillary anterior region, where probably, the resorption of the alveolar process was rapid and sophisticated; the mucosa has no bone support and becomes loose and flabby [6]. The mucosa is highly movable and loosely attached to underlying periosteum of the bone. The presence of displaceable denture-bearing tissues often presents a difficulty in making complete dentures. . Soft tissues that are displaced during impression making tends to return to their original form, and complete dentures fabricated using this impression will not fit accurately on the recovered tissues. 
This results in loss of retention, stability discomfort and gross occlusal disharmony of the dentures. So recording of those tissues in static form was utmost important. Hence, Primary impression was made in Irreversible Hydrocolloid. For Final Impression of maxillary ridge, the technique was selected aiming at recording the flabby tissue in an un-displaced or in an undistorted. Zinc oxide Eugenol impression paste is first used for making impression and then tissue is painted using impression plaster onto the displaceable tissue. Impression plaster is a Mucostatic impression material and produces little pressure. In this way, maxillary anterior area was recorded in static form.

Jaw relation was made in a usual method with extra emphasis on providing optimum free way space during Vertical jaw relationship. Neutral Zone is defined as a Potential space between lips and cheeks on one side and tongue on other side (or) the area or position where the forces between the tongue and cheeks or lips are equal [3]. Neutral zone was recorded by means of tissue conditioner and tooth was set exactly in the neutral zone. After the wax trial was completed, it was seen whether the patient's tongue was at par with the lingual cusp of the lower posterior teeth. This was done in order to gain maximum stability to mandibular denture.

\section{Conclusion}

All Prosthodontist wants to provide Successful prosthesis to satisfy the need of the patient. A thorough history making, an investigating eye in clinical examinations and other diagnostic tools leads to careful selection of optimum treatment based on sound knowledge is the key for Success in Complete denture Prosthodontics.

\section{References}

1) J Prosthet Dent (1989) Treatment of the mandibular compromised ridge: a literature review. Jennings DE 61: 575-9.

2) Beresin VE, Schiesser FJ (1976) The neutral zone in complete dentures. JProsthet Dent 95:356-367.

3) (2005) The glossary of prosthodontic terms. J Prosthet Dent 94:1092.

4) Russell AF (1959) The reciprocal lower complete denture. J Prosthet Dent 9:180-190.

5) Makzoumé JE. (2004) Morphologic compassion of two neutral zone impression techniques. J Prosthet Dent 92:563-568.

6) Prince Kumar, Kishan Singh, Ashish Kumar, Ashish Khattar, RoshniGoel, et al.(2012) Uncomplicated impression techniques for hypermobile alveolar mucosa: A hope for the hopeless. Int J Health Allied Sci 1:255-267.

7) Lytle RB (1957) The management of abused oral tissues in complete denture construction. J Prosthet Dent7:27-42.
Submit your manuscript to a JScholar journal and benefit from:

ฯ Convenient online submission

ฯ Rigorous peer review

ฯ Immediate publication on acceptance

- Open access: articles freely available online

ब High visibility within the field

ब Better discount for your subsequent articles

Submit your manuscript at

http://www.jscholaronline.org/submit-manuscript.php 